\title{
Alliance Effects, Spatial Distribution, and Interregional Technology Convergence_-A Study Based on ITISA in China
}

\author{
Zhang Baosheng*1 \\ ${ }^{1}$ School of Economics and Management, Shangqiu Normal University, Shangqiu, China
}

\begin{abstract}
Interregional technology convergence is one of the necessary conditions for the coordinated development of regional economy, and constructing cross-regional industry technology innovation strategic alliance (ITISA) is one of the main means to realize interregional technology convergence. This paper investigates whether the establishment of these alliances can improve the technological innovation ability of ITISA and its members and how ITISA and its members are distributed geographically across China. This research finds that the establishment of ITISA is conducive to the increase of the number of patent applications and the improvement of the technological innovation ability of the alliance and its members. However, due to the over-concentration of alliance members in China's eastern region and the low region coverage ratio of the single alliance, the role of the establishment of ITISA in promoting interregional technology convergence is limited.
\end{abstract}

\section{Introduction}

Interregional technology convergence is the process of realizing the convergence of technological innovation ability between regions and the decrease of the technology gap, which is also the goal pursued by every country in sustainable development. The formation of a transregional technology innovation alliance is conducive to R\&D cooperation and interactive learning among enterprises, research institutes, universities, government departments, and social service institutions in different regions, and promotes the flow of technological elements and knowledge spillover between technologically backward regions and technologically advanced regions. As shown in "Fig.1", because of the influence of technological innovation alliance, when the rate of technological progress in technologically backward regions is larger than that of advanced regions, there is a positive net outflow of technology elements and knowledge from the advanced region to the backward region, then the technological catch-up and interregional technology convergence will be realized ${ }^{[1]}$.

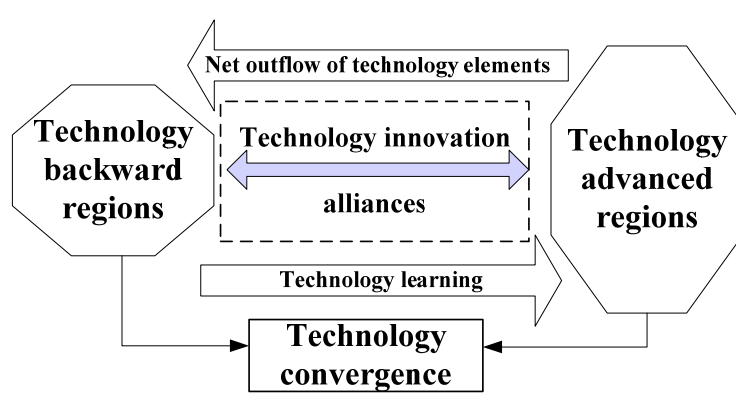

Figure 1. Technology alliance and regional technology convergence

In February 2006, China's State Council issued the "National Medium and Long-term Science and Technology Development Plan Outline (2006-2020)", which took the technology innovation system with enterprises as the dominant role and integration of industry-university-research as the breakthrough point, encouraged enterprises to establish all kinds of technology innovation alliances by uniting universities and scientific research institutes, and strengthened technological innovation ability. In December 2008, six departments including the Ministry of Science and Technology of China issued "Guiding Opinions on Promoting the Construction of ITISA", which introduced the connotation, basic principles, and basic conditions of the alliance. In June 2009, “Overall Implementation Plan of the National Technology Innovation Project" was issued by them too, which took promoting the construction and development of ITISA as one of the main tasks of the implementation of the national technology innovation project. Subsequently, "Implementation Measures (trial) 
on Promoting the Construction and Development of ITISA" set supporting measures such as the construction of policy environment, capital investment, international cooperation, supervision and evaluation. In order to study the effect of the alliance, in 2012, as one of the measures to evaluate and promote the development of alliance, "ITISA Evaluation Work Plan (try out)" was issued. Since 2014, China's ITISA has started the evaluation of activeness and published the evaluation reports.

However, there is no sufficient study investigating whether the establishment of ITISA significantly improves the technological innovation ability of ITISA and its members, promotes interregional technology convergence. To the best our knowledge, this is the first study that fully addresses the aforementioned questions and provides a comprehensive analysis of strategic alliance and its effect on innovation and interregional technology convergence in China. We find that the establishment of ITISA is conducive to the increase of the number of patent applications and the improvement of the technological innovation ability of the alliance and its members. In addition, another key contribution of this paper is to investigate how ITISA and its members are distributed geographically across China and its applications in policies. Due to the over-concentration of alliance members in China's eastern region and the low region coverage ratio of the single alliance, the role of the establishment of ITISA in promoting interregional technology convergence is limited.

The reminder of this paper is organized as follows. Section 1 covers a brief literature review of strategic alliance and its impact on technological innovation, Section 2 presents research hypotheses, the data, and methodology. The empirical analysis of whether the establishment of strategic alliances improve the technological innovation ability is presented in Section 3. Finally, Section 4 concludes.

\section{Literature Review}

A technology alliance is a union formed between different individuals in order to achieve a certain technical goal. In a narrow sense, the technology alliance mainly refers to an enterprise technology alliance, which is the activity of two or more enterprises cooperating in technological innovation. In a broad sense, technology alliance refers to an organized association formed among enterprises, universities, scientific research institutions, governments, and other social organizations in order to achieve certain technical goals. Technology alliance is divided into intraregional technology alliance and cross-regional technology alliance. If a technology alliance is a complete system formed by individual members within a region, it is called "Region Technology Alliance" (RTA). Within RTA, Technology Cell (TC) with similar industry attributes, related technology, or specific relationship can

\footnotetext{
1 According to the research of Das and Teng, when enterprises have homogeneous resources and can make use of each other, complementary alliances are easy to be formed. When enterprises have heterogeneous
}

be interconnected to form Sub-technology Alliance $(\mathrm{STA})^{[2]}$. When different units or members of an alliance are located in different regions, namely the intra-alliance connectivity is cross-regional, the Interregional technology alliance (ITA) is formed. If the intraregional technology alliance and the interregional technology alliance are connected with each other, a cross-regional technology innovation system will be formed.

Since the 1970s, preliminary studies have been conducted on strategic technology alliances in information technology, biotechnology, and new materials industries [3], but the level of cooperation was still low. In the 1980s, with the increase of inter-enterprise cooperation activities, the study of strategic alliances gradually increased ${ }^{44][5][6][7]}$. Due to different research perspectives, conclusions on the formation, motivation, governance, evolution, and performance of strategic technology alliances are also different. The main theories include dualism, social network theory, resource-based theory, dynamic capacity theory, and alliance knowledge utilization theory, etc.

For dualism, it focuses on considering the technology, financial needs or complementarities of enterprises joining alliances ${ }^{[8][9]}$, the transaction cost, dependence and imbalance of power between the two parties of the alliance ${ }^{[10][11]}$, the behavioral dynamics of alliance partners in the dynamic evolution of alliances [12][13], and the impact of partner characteristics on alliance performance $^{[14]}$.

For social network theory, it focuses on the influence of the social network on the opportunities and constraints for firms to enter the alliance ${ }^{[15][16][17]}$, the reduction of coordination costs ${ }^{[18][19][20]}$, the behavior dynamics of cross-organizational boundaries between alliance members [21][22], and the influence of the common membership relationship of partners in the alliance-onalliance performance ${ }^{[23][24]}$.

According to the resource-based theory of strategic alliance, the alliance can obtain rents by protecting and utilizing the inimitable resources ${ }^{[25][26][27]}$. The motivation of enterprises entering strategic alliances is mainly to improve their competitiveness by utilizing the resources of other alliance partners. When enterprises form a complementary alliancel due to their respective resource advantages, they will benefit each other. The resources of an enterprise can be divided into tangible resources and intangible resources, and the study of intangible resources based on knowledge and technology provides the foundation for the formation of industrial technology alliance.

The dynamic capacity theory argues that firms always acquire new capabilities through organizational learning. So, the knowledge transfer among intra-alliance enterprises has a positive influence on the technical capability improvement of partner enterprises ${ }^{[28]}$. As an important strategy in organizational learning, many

resources and can use each other, it is easy to form complementary alliances ${ }^{[29]}$. 
scholars describe the technology capacity is often acquired from alliance members, and some expansion literature also discusses the characteristics of the alliance and their participants, who promote the flow of technology-based capabilities and other knowledge among partners ${ }^{[30][31][32]}$.

Knowledge accessing theory argues that strategic alliances could help members utilize knowledge rather than acquire knowledge ${ }^{[33]}$. This is mainly because the acquisition of knowledge tends to lead to knowledge convergence among members, which leads to fierce competition and an unstable and shortened life span of the alliance. Furthermore, it is not conducive to increasing the value of the alliance. For the utilization of knowledge among members, the specialization and complementarity
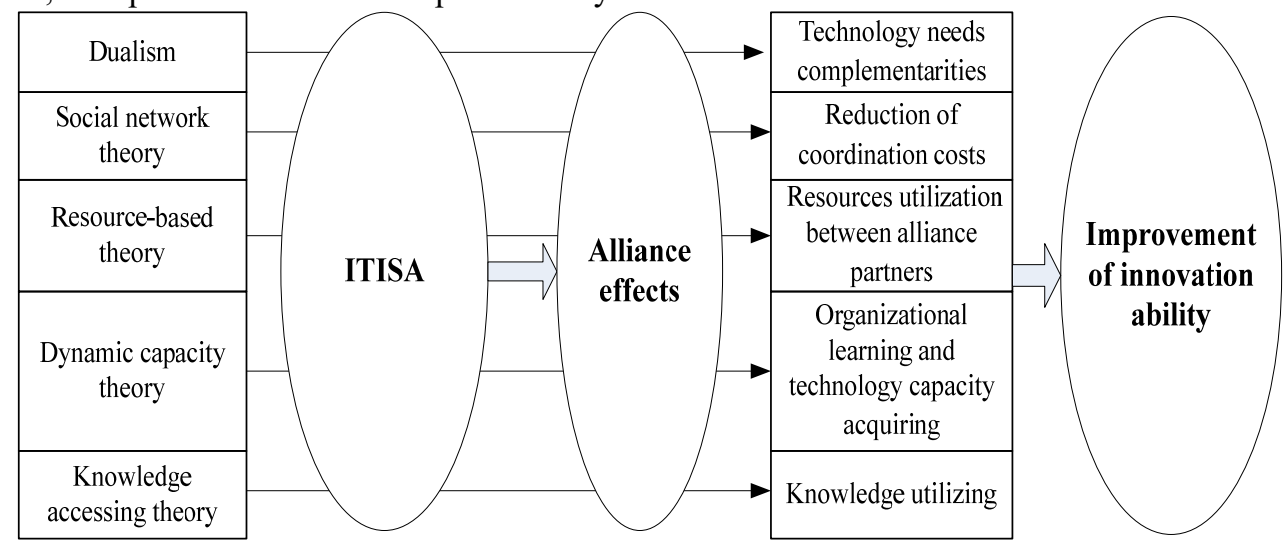

Figure 2. Different research perspectives of strategic alliance and alliance effects

\section{Analysis of Alliance Effect of China's ITISA}

\subsection{Research Hypothesis}

According to the above literature review of strategic alliance, it can be found that the formation of technology innovation strategic alliance is conducive to promoting the improvement of the innovation ability of alliance members. At the same time, a series of relevant policies are issued by China government on ITISA, whose main purpose is to promote the establishment of the technological innovation system and the formation of a regional innovation system and to enhance the technological innovation ability by encouraging the alliance of various innovation subjects.

In addition, from the samples of China's ITISA studied in this paper, each strategic alliance has the participation of enterprises, scientific research institutions, and universities, and their technological innovation is based on the industry-college-institute cooperation. Specifically, there are four modes defined as follows.

The first mode is "Project requirements - Cooperative R\&D - Intellectual property sharing - Application" (PCIA). For example, the Antibiotic Technology Innovation Strategic Alliance (ATISA) usually proposes projects according to the market demand, determines the undertaking units through bidding in alliances, establishes the research center together, shares the intellectual of knowledge among members should be fully considered, which will increase the stability and longevity of the alliance, thus increasing the value of the alliance. In addition, it is beneficial for an enterprise to participate in different alliances.

According to different research perspectives of strategic alliance, the alliance effect of five kinds of strategic alliance theories respectively focused respectively on the complementarity of technical needs, reduction of coordination costs, resource utilization between alliance partners, organizational learning and technical capability acquiring, and knowledge utilizing. These alliance effects promote the improvement of the innovation capability of alliance members (Fig. 2). 
of R\&D platforms, it forms regional collaborative innovation network between China's eastern, northeast and northwest regions. In short, all these different innovative alliances are aimed at promoting the innovation capability of alliance members. Therefore, we develop the first hypothesis as follows:

H1: the establishment of ITISA is conducive to promoting the technological innovation ability of alliance members

Further, ITISA is conducive to achieving the cooperation among alliance members and the sharing of innovation resources and improving the technical innovation ability of alliance members. In this paper, the increase in the number of patent applications is a sign of the improvement of technological capability. In order to describe the cooperation performance between alliance members more clearly, we also look up the index "the number of patents applied by alliance members jointly". In other words, the increase in the number of patents applied jointly within the alliance can better illustrate the effect of ITISA on enhancing members' technological innovation ability. Therefore, the second hypothesis is:

H2: The establishment of ITISA helps to promote the increase of the number of joint patent applications within the alliance

\subsection{Research Design}

\subsubsection{Sample selection and data sources}

The sample of this study is the patent application data of China ITISA from 1998 to 2017, and the data are collected from the website of China ITISA and Alliance member units as well as the National patent database. ITISA includes 56 national level alliances formed between 2002 and 2014, the detailed distribution of which is presented in Fig. 3 below.

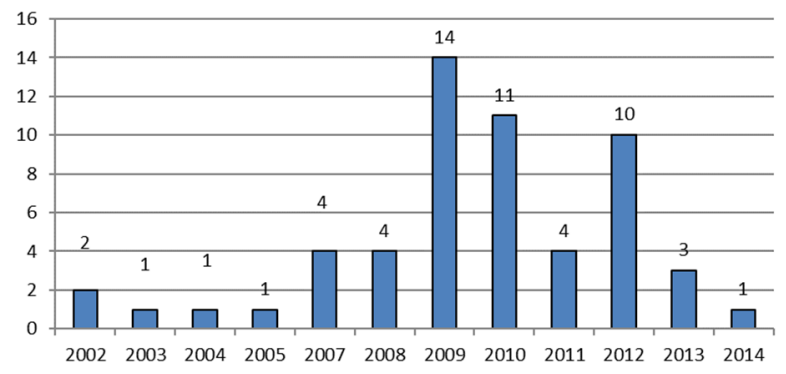

Figure 3. The number of national level alliances in different years

\subsubsection{DID method}

The selection of the experimental group and the control group is the key in the study of DID. In this paper, an alliance is regarded as an enterprise. The occurrence of alliance formation event is similar to the implementation of a "new policy" for the alliance enterprise, and the evaluation of the alliance effect is equivalent to the evaluation of the policy implementation effect. We put the alliances in top three establishing years regarding the alliance numbers into the experimental groups because the time of alliance formation is different in the 56 alliance samples. To be specific, we select 14 alliances established in 2009, 11 alliances established in 2010 and 10 alliances established in 2012 as the experimental group, while the establishment time of the other 21 alliances was relatively scattered and the number of alliances established in the same year was small, so we combined them as the control group.

2009, 2010, and 2012 are the establishment time for alliances of three experimental groups. In general, alliance effects will be generated and further promote patent applications after a year, so this paper takes 2010, 2011, and 2013 as policy implementation time.

In the analysis of DID, the dependent variable is the number of patent applications. To further control the impacts of the different number of alliance members, the different regional distribution of every member and different regional economic development level, regional R\&D spending and R\&D personnel of full-time equivalent on patent applications, we select the following control variables: the average of real GDP per capita of each alliance member's area (province), the average of internal $R \& D$ investment, and the average of $R \& D$ personnel full-time equivalent.

In order to test whether alliance formation has a significant impact on the number of patent applications, we constructed the following model:

patent $_{i t+1}=\beta_{0}+\beta_{1} *$ allitreat $_{i t}+\beta_{2} *$ alliperiod $_{i t}+\beta_{3} *$ did $+\gamma * X_{i t}+\varepsilon_{i t}$

First of all, the dependent variable patent refers to the total number of patent applications. Firstly, the explained variable patent refers to the total number of patent applications. Here, the alliance of the three experimental groups was established in 2009, 2010, and 2012 respectively, and the alliance effect was assumed to occur in 2010, 2011 and 2013 respectively. Therefore, the same control component is used for the double difference analysis. At the same time, we also further examined the impact of alliance formation on the number of joint patent applications within the alliance.

Secondly, allitreat is the group dummy variable, 1 represents the experimental group and 0 for the control group. Alliperiod is the event dummy variable, shown by 0 in the year and before the alliance establishment, 1 in the year after the alliance establishment. Did=allitreat*alliperiod is the cross-product term and is the focus of the model. $\mathrm{X}$ is the control variable group, including the average value of real GDP per capita, the average value of internal expenditure on $R \& D$ and the average value of $R \& D$ personnel FTE, represented by pagdp, rdexp and rdfte respectively.

\subsubsection{Descriptive statistics of major variables}

Annual descriptive statistics of the total amount of the alliance patent application and the joint patent application within the alliance are given as following Tab.1.

From 1998 to 2017, the total average number of the alliance patents application and the joint applied within the alliance had an increase trend, but the average number of joint applied patents within the alliance was small. At 
the same time, the standard deviations of the two variables were both large, indicating that the number of patent applications between alliances varied greatly.

TABLE I. DESCRIPTIVE STATISTICS OF MAIN VARIABLES

\begin{tabular}{llllllllll}
\hline & & allipatent & inallipa & allipatent & inallipa & allipatent & inallipa & allipatent & inallipa \\
\hline year & $\mathrm{N}$ & Mean & & Range & & Median & & Standard deviation \\
\hline 1998 & 56 & 1329.48 & 0.18 & 54111 & 4 & 207.50 & 0.00 & 7206.68 & 0.79 \\
1999 & 56 & 1677.55 & 1.04 & 66009 & 12 & 292.00 & 0.00 & 8791.88 & 2.93 \\
2000 & 56 & 2267.93 & 0.66 & 83145 & 12 & 515.50 & 0.00 & 11077.83 & 2.35 \\
2001 & 56 & 2795.11 & 2.71 & 98643 & 40 & 705.00 & 0.00 & 13111.42 & 8.37 \\
2002 & 56 & 4170.30 & 2.20 & 130136 & 37 & 1240.50 & 0.00 & 17355.69 & 7.05 \\
2003 & 56 & 5635.96 & 5.75 & 173442 & 78 & 1955.00 & 0.00 & 23035.52 & 15.43 \\
2004 & 56 & 6666.95 & 3.79 & 203190 & 34 & 2231.00 & 0.00 & 26972.99 & 7.75 \\
2005 & 56 & 8394.84 & 6.13 & 245100 & 65 & 2779.50 & 0.00 & 32578.36 & 12.48 \\
2006 & 56 & 10045.16 & 9.89 & 290174 & 168 & 3072.50 & 0.00 & 38633.78 & 27.56 \\
2007 & 56 & 11734.21 & 14.45 & 333950 & 233 & 3771.50 & 0.00 & 44422.04 & 39.61 \\
2008 & 56 & 14186.45 & 16.84 & 405573 & 277 & 4934.00 & 2.00 & 53839.87 & 43.98 \\
2009 & 56 & 17302.48 & 13.30 & 505501 & 143 & 5821.50 & 3.50 & 67150.04 & 24.37 \\
2010 & 56 & 21202.46 & 11.84 & 640269 & 112 & 7344.50 & 2.00 & 85007.53 & 21.41 \\
2011 & 56 & 28796.88 & 18.34 & 887732 & 162 & 9407.50 & 3.00 & 117776.90 & 35.04 \\
2012 & 56 & 36753.91 & 22.41 & 1199834 & 273 & 11189.50 & 6.00 & 159233.90 & 47.74 \\
2013 & 56 & 41851.43 & 53.23 & 1299768 & 779 & 13515.00 & 10.00 & 172484.70 & 126.50 \\
2014 & 56 & 48582.41 & 50.16 & 1499701 & 914 & 17106.00 & 13.50 & 198959.40 & 130.29 \\
2015 & 56 & 54323.75 & 62.30 & 1699625 & 1846 & 16282.00 & 13.00 & 225469.50 & 247.82 \\
2016 & 56 & 53124.95 & 54.95 & 1799548 & 1292 & 13588.50 & 13.00 & 238945.60 & 179.92 \\
2017 & 56 & 55639.32 & 32.29 & 2099536 & 398 & 11596.50 & 10.00 & 279085.10 & 68.65 \\
Total & 1120 & & & & & & & &
\end{tabular}

Notes: allipatent represents the total number of the alliance patents applications, inallipa represents the number of joint patent applications within the alliance.

\subsection{Empirical Analysis}

\subsubsection{The t-test of alliance effects}

According to the establishment time of the alliance, whether there is a significant difference in the mean value before and after the establishment time of the alliance was tested by t-test. It was found that both the total patent application amount of the alliance and the number of joint patent applications within the alliance all represent significant at the levels of 0.01 . This shows a significant difference in the number of patent applications before and after the establishment of the alliance (Tab.2).

TABLE 2 THE T-TEST OF ALLIANCE EFFECTS

\begin{tabular}{l|lllllll}
\hline Type & varname & obs $(0)$ & mean $(0)$ & obs $(1)$ & mean $(1)$ & mean-diff & $\mathrm{t}$ \\
\hline $\begin{array}{l}\text { Total number } \\
\text { of alliance } \\
\text { patent } \\
\text { applications }\end{array}$ & $\begin{array}{l}\text { patent20 } \\
09\end{array}$ & 420 & 4103.65 & 280 & 19187.96 & $-15084.31^{* * *}$ & -12.55 \\
& $\begin{array}{l}\text { patent20 } \\
10\end{array}$ & 416 & 3437.90 & 224 & 17877.8 & $-14439.91^{* * *}$ & -15.93 \\
patent20 & 465 & 15614.92 & 155 & 68223.45 & $-52608.53^{* * *}$ & -3.42 \\
\hline $\begin{array}{l}\text { The number } \\
\text { of joint patent }\end{array}$ & $\begin{array}{l}\text { patent20 } \\
\text { applications }\end{array}$ & 420 & 8.63 & 280 & 46.36 & $-37.72^{* * *}$ & -4.67 \\
$\begin{array}{l}\text { within the } \\
\text { alliance }\end{array}$ & $\begin{array}{l}\text { patent20 } \\
10\end{array}$ & 416 & 8.06 & 224 & 25.01 & $-16.95^{* * *}$ & -5.45 \\
\hline $\begin{array}{l}\text { patent20 } \\
12\end{array}$ & 465 & 7.70 & 155 & 21.72 & $-14.02^{* * *}$ & -5.29 \\
\hline
\end{tabular}

Notes: $* * *$ and $* * *$ indicates a significance level at $10 \%, 5 \%$, and $1 \%$ respectively. 


\subsubsection{DID analysis of alliance effects}

To investigate whether there is a significant difference in the number of patent applications before and after the establishment of the alliance, this part analyzes the impact of the establishment of ITISA on the total number of patent applications in 2009, 2010 and 2012. As can be seen from "Tab.3", the establishment of alliances at these years has a significant impact on the number of patent applications, which indicates the establishment of ITISA realized the sharing of innovation elements and the cooperation in the innovation process to some extent, and further promoted the improvement of the innovation capability of alliance members.

The joint patent application within the alliance reflects the technical innovation cooperation and resource sharing within the alliance. Tab. 4 shows that the t-test of the cross product coefficient in 2009, 2010 and 2012 are significant at the significance level of $0.01,0.05$ and 0.1 respectively, which indicates the establishment of the alliance significantly increases the technical cooperation within the alliance.

\subsection{Robust Analysis}

Firstly, this paper analyzed the effect of ITISA establishment on patent application number in 2009, 2010, and 2012. Having investigated the national science and technology policies as well as the policies mentioned in this paper with the aim of promoting the establishment of technical alliances, we did not find other any appropriate policies that can efficiently promote technical cooperation and innovation ability.

Secondly, without considering the factor of alliance effects, through the analysis of time series data of R\&D personnel, R\&D expenditures, domestic patent applications, R\&D personnel and expenditure in enterprises, institutes and universities in China since 1978, we did not find any obvious breakpoints.

Table 3 Influence of alliance establishment on the total number of alliance patent applications

\begin{tabular}{llll}
\hline varname & $\mathbf{2 0 0 9}$ & $\mathbf{2 0 1 0}$ & $\mathbf{2 0 1 2}$ \\
\hline allitreat & 1711.00 & -1296.25 & 27669.26 \\
& $(0.43)$ & $(-0.46)$ & $(0.59)$ \\
alliperio & -2054.82 & 1324.27 & -41915.13 \\
$d$ & $(-1.28)$ & $(1.03)$ & $(-2.13)$ \\
Did & $8879.395 * *$ & $8034.63 * *$ & $12398.3 * *$ \\
& $*$ & $*$ & $*$ \\
& $(5.84)$ & $(6.25)$ & $(5.87)$ \\
pagdp & -.052413 & 0.0565 & $-4.04 * * *$ \\
& $(-0.53)$ & $(0.47)$ & $(-3.38)$ \\
rdexp & -.0001092 & 0.0000914 & 0.0032 \\
& $(-0.39)$ & $(0.39)$ & $(0.87)$ \\
rdfte & $.1221802 * *$ & $.06436 * * *$ & $1.0979 * * *$ \\
& $*$ & $(4.00)$ & $(4.44)$ \\
& $(6.31)$ & & \\
Obs & 700 & 640 & 620 \\
R-sq & 0.3156 & 0.3979 & 0.1387 \\
\hline
\end{tabular}

Notes: $* * *$, and $* * *$ represent significant at the levels of $10 \%, 5 \%$, and $1 \%$ respectively.

Finally, regarding to the choice of control group in DID analysis, we select 21 alliances whose establishment time are very decentralized as a control group, the establishment time of them are between 2002 and 2013, and the maximum number of alliances formed at one time point is 4 while the minimum is 1 . When they were placed in one control group, the breakpoint in the patent data of a few alliances in one year was offset by the breakpoint effect of alliances in other years, therefore, our choice of the control group was reasonable.

Table 4 Influence of alliance establishment on the number of joint patent applications within the alliance

\begin{tabular}{llll}
\hline varname & $\mathbf{2 0 0 9}$ & $\mathbf{2 0 1 0}$ & $\mathbf{2 0 1 2}$ \\
\hline allitreat & -2.43 & -5.33 & -9.58 \\
& $(-0.14)$ & $(-0.69)$ & $(-1.51)$ \\
alliperiod & $-29.31^{*}$ & -0.31 & $-7.29 * *$ \\
& $(-1.93)$ & $(-0.06)$ & $(-1.76)$ \\
did & $59.51^{* * *}$ & $12.02^{* *}$ & $27.57 * * *$ \\
& $(4.02)$ & $(2.08)$ & $(5.93)$ \\
pagdp & 0.0002 & 0.0003 & $0.00046^{*}$ \\
& $(0.21)$ & $(0.94)$ & $(1.85)$ \\
rdexp & $4.74 \mathrm{e}-06^{*}$ & $-9.15 \mathrm{e}-07$ & $-7.93 \mathrm{e}-$ \\
& $(1.74)$ & $(-0.90)$ & $07 *$ \\
& & & $(-1)$ \\
rdfte & 0.000065 & $0.0000892^{* *}$ & 0.00005 \\
& $(0.37)$ & $(1.29)$ & $(0.99)$ \\
Obs & 700 & 640 & 620 \\
R-sq & 0.0844 & 0.068 & 0.114 \\
\hline
\end{tabular}

Notes: * **, and *** represent significant at the levels of $10 \%, 5 \%$, and $1 \%$ respectively.

\section{Spatial Distribution Characteristics of China's ITISA}

\subsection{Regional Distribution of Alliance Members}

From the regional distribution of alliance members, the 56 alliances have 2,394 members, including 384 universities, 350 scientific research institutions and 1,660 enterprises. According to the regional distribution, the mainland has 2,368 members, and 26 members are from other countries or regions.

In addition, it can be seen that most members locate in the eastern China, and the number of enterprises in the central and western China is small. According to the regional distribution of alliance members, the number of alliance members in China's eastern, central, western and northeastern regions is 1659, 300, 224 and 185 respectively, showing an obvious gradient distribution (Fig.4). 


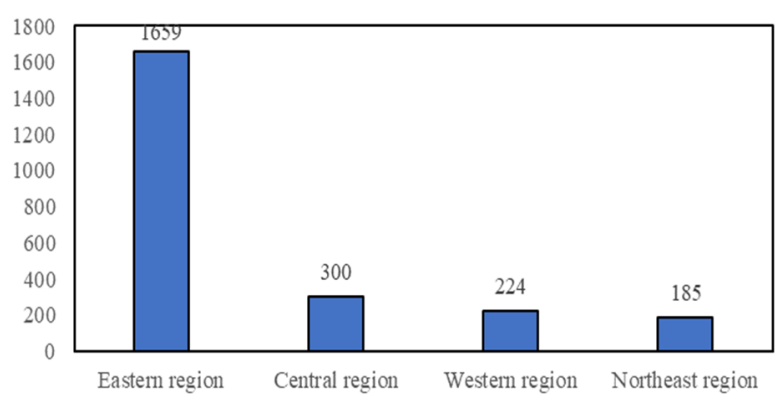

Figure 4. Region distribution of alliance members in China

\subsection{District Coverage of Alliance}

Alliance district coverage refers to the proportion of the number of distribution districts of all members in an alliance in the total 31 districts in mainland China. The average coverage rate of all 56 alliances is $37 \%$, of which the semiconductor lighting ITISA is the highest, reaching $84 \%$, followed by the ITISA of the biomass energy and the powder metallurgy industry, at $68 \%$. Changfeng Open Standards Platform Software Alliance (COSPSA) has the lowest coverage, at $9.7 \%$.

\section{Conclusion}

Using the patent application data of China ITISA from 1998 to 2017 and 56 national level alliances formed between 2002 and 2014, we conduct a thorough empirical analysis of whether the establishment of strategic alliance enhances the technological innovation ability of ITISA and its members. According to the DID analysis of the impact of alliance establishment on the patent applications, we find that the establishment of ITISA increases the number of patent applications and improve the technological innovation ability of alliance members. However, due to the over-concentration of alliance members in China's eastern region and the low region coverage ratio of the single alliance, the role of the establishment of ITISA in promoting interregional technology convergence is limited. In addition, from the spatial distribution, it is found that all members of the 56 technological innovation alliances have a high degree of regional concentration, mainly in eastern developed areas of China, regional coverage rate is low.

Our findings have further enlightenments with respect to technology convergence, policy making, and technology innovation in China.

Firstly, from the perspective of regional technology convergence, the above conclusions are not conducive to achieving coordinated development of interregional technology. Although the establishment of the alliance is conducive to improving the technological innovation capability of the alliance members, the concentrated regional distribution of the alliance members and the low district coverage rate within the alliance indicate that it is still a long road to realize the convergence of interregional technological level.

Secondly, from a policy perspective, China should encourage the establishment of cross-regional technology alliances, especially the industry technology innovation strategic alliances by enterprises, research institutions and universities between economically and technologically developed regions and undeveloped regions, realize the trans-regional flow of innovation factors, and promote the coordinated development of interregional technology.

Finally, the increase in the number of patent applications is one of the external manifestations of the improvement of technological innovation ability, but the commercialization of patent achievements is a necessary condition to promote the development of regional economy. How technology alliance promotes technology commercialization needs to be further studied on this basis.

\section{Acknowledgements}

This paper is supported by Program for Innovative Research Team (in Science and Technology) in University of Henan Province of China (Grant No. 19IRTSTHN016), National Social Science Foundation of China (Grant No. 17BJL056).

\section{References}

1. Zhang, B.S. (2016) Research on technological convergence in coordinated development of regional economy. China Economic Press, pp. 192-193.

2. Yang, W.N., X.L. Liu and Y. Zou. 2008. Research on the security of innovation resource sharing in regional large technology alliance. Science of science and management of science and technology, 10: pp. 134-139.

3. Hagedoorn, J. and J. Schakenraad. 1990. Strategic partnering and technological cooperation. In B. Dankbaar, J. Groenewegen, and H. Schenk (Eds.), Perspectives in Industrial Economics. Dordrecht: Kluwer, pp. 171-191.

4. Hladik, K. J. 1985. International Joint Ventures, Lexington, MA: Lexington Books.

5. OECD. 1986. Technical Cooperation Agreements between Firms: Some Initial Data and Analysis. Paris: OECD.

6. Chesnais, F. 1988. Technical co-operation agreements between firms. STI Review 4: 51-119.

7. Mytelka, L. K. 1991. Strategic Partnerships and the World Economy. London: Pinter.

8. Pfeffer, J. and P. Nowak. 1976. Joint venture and interorganizational interdependence. Administrative Science Quarterly, 21(3), pp. 398-418.

9. Mariti, P. and R. H. Smiley. 1983. Co-operative agreements and the organization of industry. Journal of Industrial Economics, 31(4), pp. 437-451.

10. Pisano, G. P., M. V. Russo and D. Teece. 1988. Joint ventures and collaborative arrangements in the telecommunications equipment industry. In D. Mowery (ed.), International Collaborative Ventures in U.S. Manufacturing. Ballinger, Cambridge, MA, pp. 23-70. 
11. Harrigan, K. R. 1987. Strategic alliances: Form, autonomy and performance. working paper, Columbia University.

12. Ring, P. S. and A. H. Van De Ven. 1994. Developmental processes of cooperative interorganizational relationships. Academy of Management Review, 19(1), pp. 90-118.

13. Doz, Y. 1996. The evolution of cooperation in strategic alliances: Initial conditions or learning processes. Strategic Management Journal, Summer Special Issue, 17, pp. 55-83.

14. Harrigan, K. R. 1986. Managing for Joint Ventures Success. Lexington Books, Lexington, MA.

15. Kogut, B., W. Shan and G. Walker. 1992. The make or cooperate decision in the context of an industry network. In N. Nohria and R. Eccles (eds.), Networks and Organizations. Harvard Business School Press, Cambridge, MA, pp. 348-365.

16. Gulati, R. 1995a. Social structure and alliance formation pattern: A longitudinal analysis. Administrative Science Quarterly, 40, pp. 619-652.

17. Gulati, R. and J. Westphal. 1997. The dark side of embeddedness: An examination of the influence of direct and indirect board interlocks and CEO/board relationships on interfirm alliances. Working paper, J. L. Kellogg Graduate School of Management, Northwestern University.

18. Zajac, E. J. and C. P. Olsen 1993. From transaction cost to transactional value analysis: Implications for the study of interorganizational strategies. Journal of Management Studies, 30(1), pp. 131-145.

19. Gulati, R. 1995b. Does familiarity breed trust? The implications of repeated ties for contractual choice in alliances. Academy of Management Journal, 38, pp. 85-112.

20. Gulati, R. and H. Singh. 1997. The architecture of cooperation: Managing coordination costs and appropriation concerns in strategic alliances. Administrative Science Quarterly, forthcoming.

21. Nohria, N. and C. Garcia-Pont. 1991. Global strategic linkages and industry structure. Strategic Management Journal, Summer Special Issue, 12, pp. 105-124.
22. Gomes-Casseres, B. 1994. Group versus group: How alliance networks compete. Harvard Business Review, 72(4), pp. 62-74.

23. Levinthal, D. A. and M. Fichman. 1988. Dynamics of interorganizational attachments: Auditor-client relationships. Administrative Science Quarterly, 33, pp. 345-369.

24. Gulati, R. and P. Lawrence 1997. Organizing vertical networks: A design perspective. Working paper, J. L. Kellogg Graduate School of Management, Northwestern University.

25. Penrose, E. T. (1959). The Theory of the Growth of the Firm. Wiley, New York.

26. Barney, J. B. 1986. Strategic factor markets: Expectations, luck, and business strategy. Management Science, 32 (10), pp. 1231-1241.

27. Wermerfelt, B. 1984. A resource-based view of the firm. Strategic Management Journal, 5 (2), pp. 171180.

28. Das, T.K. and B.S. Teng. 2000. A resource-based theory of strategic alliances. Journal of management, 26(1), pp31-36.

29. Mowery, D.C., J.E. Oxley and B.S. Silverman. 1996. Strategic alliances and interfirm knowledge transfer. Strategic Management Journal 17, 77-91.

30. Kogut, B. (1988) Joint ventures: Theoretical and empirical perspectives. Strategic Management Journal,9 (4), pp. 319-332.

31. Cohen, W. M. and D. A. Levinthal ( 1990 ) Absorptive capacity: A new perspective on learning and innovation. Administrative Science Quarterly, 35, pp. 128-152.

32. Hamel, G. (1991) Competition for competence and inter-partner learning within international strategic alliances. Strategic Management Journal, Summer Special Issue, 12, pp.83-103.

33. Grant, R.M. and C. Baden-Fuller (2004) A Knowledge Accessing Theory of Strategic Alliances. Journal of Management Studies 41:1 January,00222380 . 